\title{
Knowledge of Drug Information Resources among Students of College of Pharmacy and Nursing, University of Nizwa in Oman
}

\author{
Abdul Hakeem Mohammed Ali Al-Saidi ${ }^{1}$, Sujith Haridass ${ }^{1}$, Ahmed Nouri ${ }^{\star}$, Mohamed Azmi Hassali ${ }^{3}$, Tuqa Allayla ${ }^{3}$ and Osama Helweh ${ }^{4}$ \\ ${ }^{1}$ College of Pharmacy and Nursing, University of Nizwa, Malaysia \\ ${ }^{2}$ Discipline of Clinical Pharmacy, Universiti Sains Malaysia, Pulau Pinang, Malaysia \\ ${ }^{3}$ Discipline of Social and Administrative Pharmacy, Universiti Sains Malaysia, Pulau Pinang, Malaysia \\ ${ }^{4}$ Faculty of Pharmaceutical Sciences, UCSI University, Kuala Lumpur, Malaysia
}

*Corresponding author: Ahmed Ibrahim Nouri, Discipline of Clinical Pharmacy, Universiti Sains Malaysia, Pulau Pinang, Malaysia, Tel: +60124210209; E-mail: ahmad090@hotmail.com

Received date: May 10, 2018; Accepted date: May 16, 2018; Published date: May 24, 2018

Copyright: @ 2018 Al-Saidi AHMA, et al. This is an open-access article distributed under the terms of the Creative Commons Attribution License, which permits unrestricted use, distribution, and reproduction in any medium, provided the original author and source are credited.

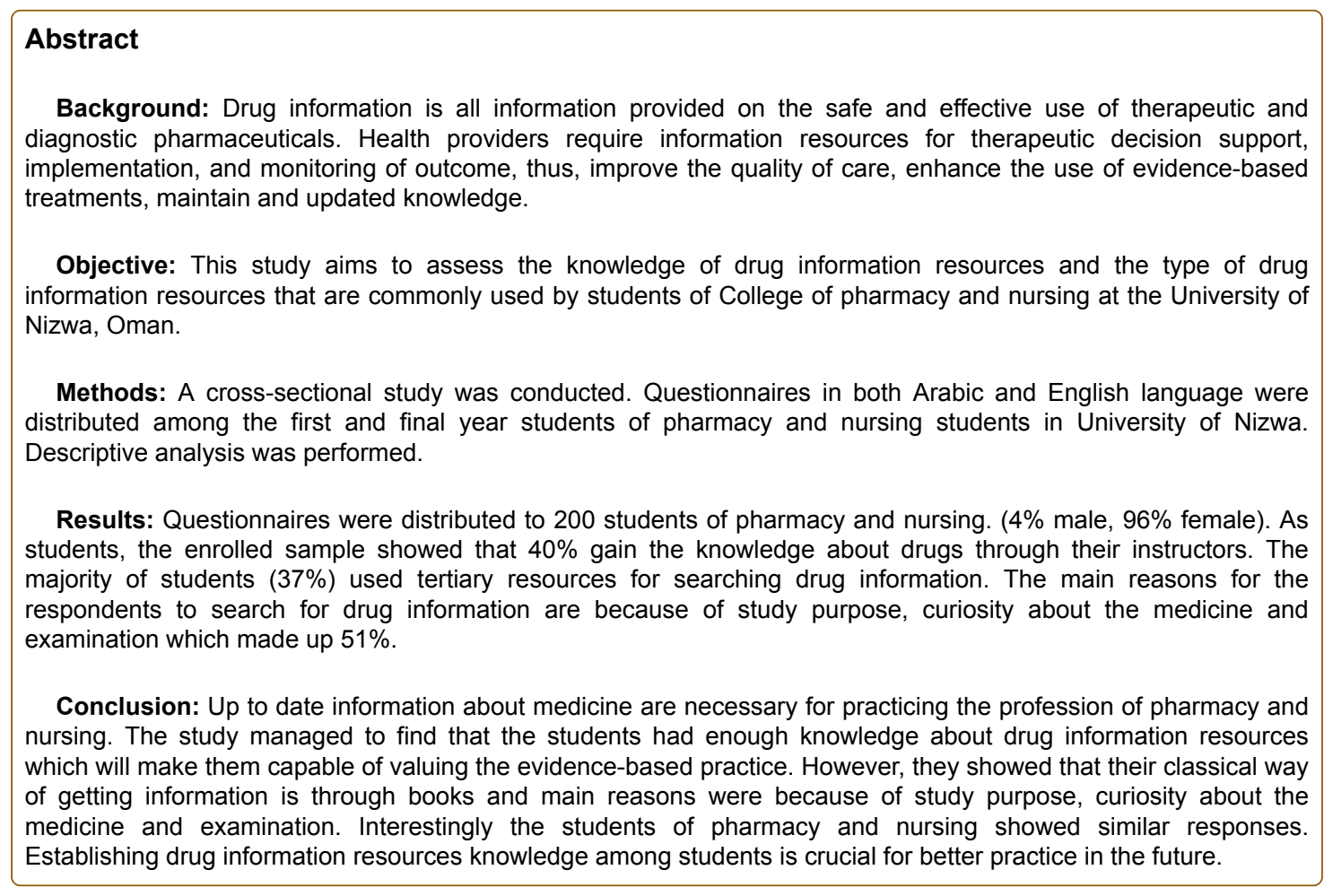

Keywords: Drug information; Students; Knowledge; Resources; Pharmacy; Nursing

\section{Introduction}

The overall amount of medical information is growing. There is a vast amount of data on drugs that are approved by the Food and Drug Administration (FDA), and on agents undergoing clinical investigation [1]. Drug information is the process of providing information on the safe and effective use of therapeutic and diagnostic pharmaceuticals.

Sources of information are categorized as primary, secondary or tertiary depending on their originality and their proximity to the source or origin [1,2]. Primary literature forms are the foundation of the literature hierarchy. It is the source of information for the development of secondary and tertiary literature resources [2]. The primary source is comprised of original research that is written by the author. Most primary source contains a detailed description of the study design, methodology and scientific result [3]. A secondary source of information works of synthesis and interpretation based upon primary resources and the work of other authors. They may take a variety of forms. The authors of secondary sources develop their interpretations and narratives of events based on primary sources, that is, documents and other evidence created by participants $[2,3]$. Tertiary resources are published or unpublished works that are based on secondary sources. Tertiary resources are index to primary resources. Also, it consists of information which is a distillation and collection of primary and secondary resources. Tertiary references may be of textbooks on various drug or disease topics (e.g., pharmacotherapy), compendia (a vast array of information about many drugs such as the Physician's Desk Reference) or online, full-text databases [2]. Different levels of drug information are required by healthcare providers and recipients. Medical practitioners and pharmacists need access to the information required by regulatory 
authorities for new drugs. Healthcare workers who have limited prescribing authority require a subset of this information together with protocols for diagnosis and treatment. All health providers require information resources for therapeutic decision support, implementation, and monitoring of outcomes. People receiving medication need instruction for the use of prescribed and over-thecounter medicines. Additional information may be necessary for highrisk groups (e.g., pediatrics, geriatrics, pregnancy, and breastfeeding) and in some diseases (e.g., diabetes, kidney and liver dysfunction) [4].

Many studies related to medicines information were conducted in other countries. McGowan et al. examined the educational implications of the World Wide Web as a primary source of health information in medical practice and offer curricular objectives to educate the next generation of physicians to be competent in using the Web. McGowan, emphases to the need for systematic, reproducible assessment models for these websites $[4,5]$.

Peterson et al. monitored second-year medical students' use of a unique digital textbook, Up To Date, as they transitioned from preclinical to clinical years at the University of Iowa. Students were surveyed about their preferred clinical information resources. The study demonstrates that medical students embrace and use electronic information resources much more than it has been reported among practicing clinicians [6].

Mahrana et al. conducted a survey on the use of information and communication technology among medical students. The study showed that $77.34 \%$ of the students had the opinion that Information and Communication Technology (ICT) should be included in undergraduate syllabus and $97.65 \%$ of students express the desire for a computer lab in their college $78.12 \%$ of the respondents of the survey had opinion that medical education would not be effective without Information and Communication Technology (ICT) [7].

Northup et al. conducted a survey on characteristics of clinical information-searching among medical students, residents, and physicians. The study showed that the medical students sought overview or background information in books (49\%) and factual or subjects specific information in journal articles $(21 \%)$. Among the study population of physicians, the purpose for searching information was for therapeutic reasons (50\%) while $32 \%$ indicated the need for diagnostic information and $13 \%$ for etiological information and $5 \%$ for epidemiological information. The study showed that medical students relied heavily on books (49\%) colleagues (24\%) and journals/article (21\%) for clinical information. The study results revealed the need to educate Medical students to tailor information search strategy and to retrieve information from a variety of resources outside the personal library [8].

Romanov et al. conducted a survey on use of electronic scientific resources among medical and dental students shown that $24 \%$ and $19 \%$ of the dental students searched MEDLINE more than two times per month for study purpose, and $32 \%$ of medical students and $22 \%$ dental students search for research purpose $12 \%$ of the respondents never utilized either MEDLINE or full-text articles. The study recommended having adequate training in information searching skills for students [9].

There are many sources of information available that can help an individual pharmacist or health care professional to answer drugrelated questions. Studies had shown that electronically available information systems by medical professionals can improve the quality of care, enhance the use of evidence-based treatments, maintain and update knowledge. The major goal of medical education is to encourage students to maintain their knowledge of medical science by becoming lifelong learners. The key elements in the process of lifelong learning are the skills in information seeking and regular use of scientific sources. Therefore, this study aims to assess the knowledge of drug information resources and the type of Drug information resources that are commonly used by students of College of pharmacy and nursing, University of Nizwa.

The study's results will help the educators and administrators of the University of Nizwa to analyze the existing facilities for drug information resources and provide adequate training in their drug information searching skills.

\section{Methodology}

A cross-sectional study, questionnaire-based, was conducted among the first year and final year Pharmacy and nursing students at University of Nizwa campus, Oman. A Self-administered 11-items questionnaire was used to assess the knowledge of drug information resources among the students. This study was carried out from March 2015 to May 2015. A total sample of 200 students comprising of 100 pharmacy students (50 first-year students and 50 final year students) and 100 nursing students (50 first-year students and 50 final year students) were enrolled into the study.

The study included first and final year pharmacy and nursing students of College of pharmacy and nursing, University of Nizwa. While the study excluded students in specialties other than pharmacy and nursing and foundation institute students.

After obtaining the permission to conduct the study from the school of pharmacy committee, the questionnaire (both in Arabic and English language) was distributed among the first and final year students of pharmacy and nursing. The participants were informed about the nature of the study and the procedure to complete the questionnaire. The students who met the inclusion criteria of the study and were willing to participate in the study were enrolled. The questionnaires were collected back from the participants, and the data was entered, arranged and filtered in excel sheet then exported to SPSS statistical software, version 15.0

\section{Results}

The study had a total sample of 200 students. Out of total study sample $4 \%$ of the respondents where male and $96 \%$ were female. Among the pharmacy group, 95\% were female while among nursing category $97 \%$ were female. The percentage of the male in pharmacy and nursing were $5 \%$ and $3 \%$ respectively.

Overall, the entire sample strongly agrees that drug information must always be up-to-date for professionals practicing in pharmacy or nursing. In addition, if the sample is drawn across Pharmacy specialization (within degree and year) and across Nursing specialization (within diploma degree and at bachelor final year), Study showed relatively same agreement category as the entire sample. Table 1 shows the disaggregated mean score agreement of the respondents to the statement "Up-to-date information about medicines is necessary for practicing the profession of Pharmacy/Nursing." 
Citation: $\quad$ Al-Saidi AHMA, Haridass S, Nouri A, Hassali MA, Allayla T, et al. (2018) Knowledge of Drug Information Resources among Students of College of Pharmacy and Nursing, University of Nizwa in Oman. J Health Educ Res Dev 6: 260. doi:10.4172/2380-5439.1000260

Page 3 of 5

\begin{tabular}{|c|c|c|c|}
\hline \multirow{2}{*}{ Specialization } & \multirow{2}{*}{ Degree } & Mean & \multirow{2}{*}{$\mathrm{Vl}^{\mathrm{a}}$} \\
\hline & & (first; final) & \\
\hline \multirow{4}{*}{ Pharmacy ${ }^{b}$} & \multirow{2}{*}{ Diploma } & 3.82 & \multirow{2}{*}{ Strongly Agree } \\
\hline & & $(3.92 ; 3.72)$ & \\
\hline & \multirow{2}{*}{ Bachelor } & 3.84 & \multirow{2}{*}{ Strongly Agree } \\
\hline & & $(3.88 ; 3.80)$ & \\
\hline \multirow{4}{*}{ Nurse $^{c}$} & \multirow{2}{*}{ Diploma } & 3.88 & \multirow{2}{*}{ Strongly Agree } \\
\hline & & $(3.88 ; 3.88)$ & \\
\hline & \multirow{2}{*}{ Bachelor } & 3.62 & \multirow{2}{*}{ Strongly Agree } \\
\hline & & $(3.24 ; 4.00) d$ & \\
\hline \multicolumn{2}{|l|}{ Overall } & 3.79 & Strongly Agree \\
\hline
\end{tabular}

Table 1: Importance of up-to-date drug information in practice.

Generally, all the respondents believe that effectiveness of medical education is attainable along with the integration of scientific resources in teaching and learning situations. Moreover, the Nursing specialization and Pharmacy specialization have a relatively the same perception. On the other hand, there is a significant difference in the mean score agreement between the first year and final year of Diploma in Pharmacy specialization. This translates to the fact that on the average, the diploma first-year pharmacy students are not sure about if the integration of scientific resources can lead to an effective medical education. Table 2 shows the disaggregated mean score agreement of the respondents to the statement "Medical education will not be effective unless information seeking skills and regular use of scientific sources are used in the educational process."

\begin{tabular}{|c|c|c|c|}
\hline \multirow{2}{*}{ Specialization } & \multirow{2}{*}{ Degree } & Mean & \multirow{2}{*}{$\mathbf{V l}^{\mathbf{a}}$} \\
\hline & & (first; final) & \\
\hline \multirow{4}{*}{ Pharmacy ${ }^{b}$} & \multirow{2}{*}{ Diploma } & 3.58 & \multirow{2}{*}{ Agree } \\
\hline & & $(3.24 ; 3.92) d$ & \\
\hline & \multirow{2}{*}{ Bachelor } & 3.8 & \multirow{2}{*}{ Agree } \\
\hline & & $(3.60 ; 4.00)$ & \\
\hline \multirow{4}{*}{ Nurse ${ }^{c}$} & \multirow{2}{*}{ Diploma } & 3.84 & \multirow{2}{*}{ Agree } \\
\hline & & $(3.92 ; 3.76)$ & \\
\hline & \multirow{2}{*}{ Bachelor } & 3.74 & \multirow{2}{*}{ Agree } \\
\hline & & $(3.25 ; 4.00)$ & \\
\hline \multicolumn{2}{|l|}{ Overall } & 3.74 & Agree \\
\hline \multicolumn{4}{|c|}{ aMean score within $3.25-4.00$ is 'Agree'; $2.50-3.24$ is 'Not Sure' } \\
\hline
\end{tabular}

Table 2: The effectiveness medical education.
The results show that the two groups of respondents are not sure about the availability of sources of drug information at the University Campus. The study showed similar findings when the data was disaggregated across two specializations (both within diploma and at first-year bachelor). However, within the bachelor degree of each specialization, there is a significant difference between the first and final year students. Table 3 shows the disaggregated mean score agreement of the respondents in question number 3 "Drug information resources are available in the University Campus."

\begin{tabular}{|c|c|c|c|}
\hline \multirow{2}{*}{ Specialization } & \multirow{2}{*}{ Degree } & Mean & \multirow{2}{*}{$\mathbf{V}^{\mathrm{a}}$} \\
\hline & & (first; final) & \\
\hline \multirow{4}{*}{ Pharmacy ${ }^{b}$} & \multirow{2}{*}{ Diploma } & 3.22 & \multirow{2}{*}{ Not Sure } \\
\hline & & $(3.24 ; 3.20)$ & \\
\hline & \multirow[b]{2}{*}{ Bachelor } & 3.26 & \multirow[b]{2}{*}{ Agree } \\
\hline & & $(3.00 ; 3.52) d$ & \\
\hline \multirow{4}{*}{ Nurse ${ }^{c}$} & \multirow[b]{2}{*}{ Diploma } & 3.12 & \multirow[b]{2}{*}{ Not Sure } \\
\hline & & $(2.96 ; 3.28)$ & \\
\hline & \multirow{2}{*}{ Bachelor } & 3.18 & \multirow{2}{*}{ Not Sure } \\
\hline & & $(2.84 ; 3.52) \mathrm{d}$ & \\
\hline \multicolumn{2}{|l|}{ Overall } & 3.2 & Not Sure \\
\hline \multicolumn{4}{|c|}{ aMean score within $3.25-4.00$ is 'Agree'; $2.50-3.24$ is 'Not Sure' } \\
\hline \multicolumn{4}{|c|}{ bMean score is 3.24 'Mean score is $3.15^{d}$ Significant at $\alpha=0.05$} \\
\hline
\end{tabular}

Table 3: The Availability of Drug information resources within UON Campus.

Most of the respondents (34\%) use the network access provided on University of Nizwa campus in seeking drug information resources. On the other hand, it appears that only $24 \%$ of the respondents search 
information about medicine at home or directly to the University of Nizwa's website.

Questions about types of sources used for searching drug information used by the respondents in searching information about a medicine allowed the study to find the classical way of getting information which is through books (23\%). While $9 \%, 7 \%$, and $15 \%$, of the respondents used package leaflets, databases, and journals, respectively as their resource in searching information about the medicine. Regularity of searching information about medicine showed that the majority of the respondents only search for information about medicine only when they are required to do. This comprises about $52 \%$ of the total respondents. Regarding the reasons for searching information about the medicine, the main reasons for the respondents to search are because of study purpose $(21 \%)$, curiosity about the medicine (15\%) and examination (15\%).

The percentage distribution of the respondents' preference in searching or consulting with factual information about a medicine showed that books are the most widely used by the respondents (29\%) in their search for factual information about a medicine. Magazines, journals, blogs, and forums are seldom preferred by the respondents (10\%).

Regarding participation in course/training program related to drug information searching skills, the majority of the respondents $(82 \%)$ stated that they did not learn any course nor attended any training program on how to find the information using drug information resources in the past. However, almost all the respondents wanted to be trained and gain skills related to drug information resources.

\section{Discussion}

The results of the study show that most of the respondents have strongly agreed that the up-to-date drug information is necessary for practicing the profession of pharmacy or nursing. A Study was done by Repchinsky et al. showed that the importance of up to date information emerges in search of information about new drugs which is not yet documented in the tertiary resources [10]. The study results demonstrate all the respondents agree that effectiveness in medical education will be attainable by the regular use of scientific resources in the educational process. A Study was done by Maharana et al. showed that $80 \%$ of the medical students agreed that medical education would not be effective without the use of information and communication technology and the information searching techniques should be part of medical education [7]. The respondents of this study were not sure about the availability of Drug information resources within University of Nizwa campus. The study results showed that $40 \%$ of the total sample acquired the knowledge about drug information resources through their instructors or teachers and 19\% through the librarian on their course of stay at the University. On the other hand, a study was done by Northup et al. revealed that $20 \%$ of the participants acquired their knowledge of information sources through their colleagues/fellow students, and $19 \%$ gained this information from medical education and training [11].

The responses by the participants of the study showed that $34 \%$ used network access within the campus provided by the University of Nizwa, and 25\% used the university library as location of search for drug information while $24 \%$ of the respondents accessed the drug information at home directly or through the University of Nizwa's website. A study was done by Northup et al. showed that $64 \%$ of medical students accessed personal libraries and reprinted files of journals, while $33 \%$ used the library as a source of medical information [11].

The majority of the participants (37\%) used tertiary resources for searching drug information. The study shows the high dependence of pharmacy students on ONF and BNF (13\%) comparing to nursing students (1\%) that may be due to the availability of ONF and BNF with pharmacy students. A study was done by Northup et al. showed that medical students relied heavily on books (49\%), colleagues $(24 \%)$, and journals/ article (21\%) [11]. The study results demonstrate that the minority of students search for drug information in regular basis while $52 \%$ of the respondents search for drug information only when required. A study was done by Romanov et al. showed that $24 \%$ of medical students and $19 \%$ of dental students search MEDLINE more than two times per month for study purpose, and 32\% of medical students and $22 \%$ dental students search for research purpose [9].

The study results show that the main reasons for the respondents to search for drug information are because of study purpose, curiosity about the medicine and examination. These reasons made up the majority of the respondents' perception which is about $51 \%$. On the contrary, only $11 \%$ of the respondents said that it is habitual and about $2 \%$ said that it is embedded in their coursework. A study was done by Northup et al. showed that among the study population of physicians; the purpose for searching information was for therapeutic reasons (50\%) while $32 \%$ indicating the need for diagnostic information and $13 \%$ for etiological information and $5 \%$ for epidemiological information [11]. The study results show that most of the respondents prefer to refer to a book to collect background and factual information about the medicine. This is about $25 \%$ and $29 \%$ respectively. Magazines, journals, blogs, and forums are seldom preferred by the respondents $(21 \%)$. On the other hand, the study done by Northup et al. showed that the medical students sought overview or background information in books (49\%) and factual or subjects specific information in a journal article (21\%) [11].

The majority of the respondents (82\%), said that they did not learn any course nor attended any training program on how to find the information using drug information resources in the past, even though the process of drug information is covered in the curriculum of pharmacy and nursing program. Almost all the participants show the willingness to attend any training program on drug information resources in the future (98\%). Study done by Maharana et al. showed that $77.3 \%$ of the medical students have the opinion that information and communication technology should be included in the undergraduate MBBS syllabus [7]. The study recommends conducting information search education in the preliminary year of study and so that the students will be exposed to a variety of possible information resources and their characteristics. It is highly recommended to have a student orientation program on library facilities /resources.

\section{Conclusions}

This study aims to evaluate the knowledge on source of drug information among pharmacy and nursing students of the University of Nizwa. Most of the students strongly agree that up to date information about medicine are necessary for practicing the profession of pharmacy and nursing. Generally, all the respondents believe that effectiveness of medical education is attainable along with the integration of scientific resources in teaching and learning situations. Most of the respondents are not sure about the availability of sources of drug information at the University Campus. Most of the respondent 
Citation: $\quad$ Al-Saidi AHMA, Haridass S, Nouri A, Hassali MA, Allayla T, et al. (2018) Knowledge of Drug Information Resources among Students of College of Pharmacy and Nursing, University of Nizwa in Oman. J Health Educ Res Dev 6: 260. doi:10.4172/2380-5439.1000260

Page 5 of 5

appears to have acquired knowledge about drug information resources through their instructors or teachers at school. Most of the respondents use the network access provided on University of Nizwa campus in searching drug information. Clearly, the respondents showed that the classical way of getting information is through books. Majority of the respondents only search for information about medicine only when they are required to do so. Overall, the main reasons for the respondents for medicine search are because of study purpose, curiosity about the medicine and examination. The study results show that most of the respondents prefer to refer to books to collect background and factual information about medicine. Majority of the respondents did not learn any course nor attended any training program on how to find the information using drug information resources in the past. Almost all the participants show the desire to attend training program on drug information resources in future.

\section{References}

1. Knoben JE, Phillips SJ (2014) New drug information resources for pharmacists at the National Library of Medicine. Journal of the American Pharmacists Association 54: 49-55.

2. Sharp M, Bodenreider O, Wacholder N (2008) A framework for characterizing drug information sources. AMIA Annu Symp Proc 6: $662-666$.
3. Boorkman JA, Huber JT, Roper FW (2004) Introduction to reference sources in the health sciences. Neal-Schuman Publishers.

4. Närhi U (2007) Sources of medicine information and their reliability evaluated by medicine users. Pharm World Sci 29: 688-694.

5. McGowan JJ, Berner ES (2004) Proposed curricular objectives to teach physicians competence in using the World Wide Web. Academic Medicine 79: 236-240.

6. Peterson MW, Rowat J, Kreiter C, Mandel J (2004) Medical students' use of information resources: Is the digital age dawning?. Academic Medicine 79: 89-95.

7. Maharana B, Biswal S, Sahu N (2009) Use of information and communication technology by medical students: A survey of VSS Medical College, Burla, India. Library Philosophy and Practice (e-journal), p: 281.

8. Buck ML (1998) Providing patients with written medication information. Ann Pharmacother 32: 962-969.

9. Romanov K, Aarnio M (2006) A survey of the use of electronic scientific information resources among medical and dental students. BMC Med Edu 6: 28.

10. Repchinsky C (2001) Up-to-date drug information. Can Fam Physician 47: 1545.

11. Northup DE, Moore-West M, Skipper B, Teaf SR (1983) Characteristics of clinical information-searching: investigation using critical incident technique. J Med Educ 58: 873-881. 